\title{
Haemorrhagic disease of the newborn in the British Isles: two year prospective study
}

\author{
Andrew W McNinch, John H Tripp
}

\begin{abstract}
Objective-To determine the incidence of haemorrhagic disease of the newborn in the British Isles, study risk factors, and examine the effect of vitamin $\mathrm{K}$ prophylaxis.

Design-Prospective survey of all possible cases of haemorrhagic disease of the newborn as reported by consultant paediatricians using the monthly notification cards of the British Paediatric Surveillance Unit and a follow up questionnaire for each case to validate the diagnosis and accrue further data.
\end{abstract}

Setting-Britain (England, Scotland, and Wales) and Ireland (Northern Ireland and the Irish Republic) during December 1987 to March 1990.

Patients -27 infants classified as having confirmed $(n=25)$ or probable $(n=2)$ haemorrhagic disease of the newborn.

Results -24 of the 27 infants were solely breast fed. 10 suffered intracranial haemorrhage; two of these died and there was clinical concern about the remainder. 20 infants had received no vitamin $K$ prophylaxis, and seven had received oral prophylaxis. Relative risk ratios for these groups compared with babies who had received intramuscular vitamin $K$ were 81:1 and 13:1 respectively. Six infants had hepatitis $\left(\alpha_{1}\right.$ antitrypsin deficiency in four), unsuspected until presentation with haemorrhagic disease of the newborn, of whom four had received oral prophylaxis. One other baby had prolonged jaundice. One mother had taken phenytoin during pregnancy.

Conclusions-All newborn infants should receive vitamin $K$ prophylaxis. Intramuscular vitamin $K$ is more effective than oral prophylactic regimens currently used in the British Isles.

\section{Introduction}

It is almost 50 years since Dam and Doisy were jointly awarded the Nobel prize for medicine or physiology for the isolation of vitamin $K_{1}$ from alfalfa and since the first trials showed that it protected against haemorrhagic disease of the newborn. ${ }^{1}$ Although occasional cases of haemorrhagic disease of the newborn continue to be reported, most paediatricians will not see a single case in several years, allowing the impression that it is no longer a significant cause of morbidity and mortality. If that impression is false there are important implications for the use of vitamin $K$ prophylaxis as there is no uniform practice in the British Isles. ${ }^{23}$ Using the system developed and organised by the British Paediatric Surveillance Unit, ${ }^{4}$ we have conducted a prospective survey of haemorrhagic disease of the newborn in the British Isles to determine its incidence, learn more about the condition, and investigate the efficacy of current methods of prophylaxis.

\section{Subjects and methods}

Cases of haemorrhagic disease of the newborn were enrolled in the study over two years from March 1988 to February 1990 by means of the report card system of the British Paediatric Surveillance Unit. For the study a case of haemorrhagic disease of the newborn was defined as: "Any infant under six months of age with spontaneous bruising/bleeding or intracranial haemorrhage associated with prolonged clotting times, not due to an inherited coagulopathy or disseminated intravascular coagulation." Paediatricians were asked to notify any proved or suspected case and subsequently to complete a questionnaire giving further details of each case, including data regarding pregnancy and delivery, use of vitamin $\mathrm{K}$ prophylaxis, method of feeding, mode and timing of presentation, underlying illness in the baby, laboratory findings, and outcome. Birth population data were obtained for Great Britain and Northern Ireland from the Office of Population Censuses and Surveys and for the Republic of Ireland from the Central Statistics Office, Dublin.

\section{Results}

In the 24 months during which haemorrhagic disease of the newborn was included among the conditions reportable to the British Paediatric Surveillance Unit $90 \%$ of all report cards were returned. In the first nine months there may have been underreporting because the condition was listed on the cards as "HDN," interpreted by some to mean haemolytic disease of the newborn; thereafter the full name "haemorrhagic disease of the newborn" was used on the cards.

Over the two years 78 cases were notified. A questionnaire for each case was sent to the reporting paediatricians, and the 70 returned allowed classification into one of four groups. These were $(a)$ confirmed haemorrhagic disease of the newborn (appropriate history of haemorrhage, documented prolonged clotting times, normal or raised platelet count, no evidence of infection; $\mathrm{n}=25)$; (b) probable haemorrhagic disease of the newborn (appropriate history, diagnosis other than haemorrhagic disease of the newborn thought unlikely but lacking laboratory confirmation; $\mathrm{n}=2) ;(c)$ possible haemorrhagic disease of the newborn (incomplete data causes for bleeding other than haemorrhagic disease of the newborn thought likely; $\mathrm{n}=13$ ); and (d) "no case" (dubious history and incomplete data or confirmation of serious disease other than vitamin $\mathrm{K}$ deficiency which would predispose to bleeding - for example, thrombocytopenia (one case), disseminated intravascular coagulation (one case), extreme prematurity with complications (one case) $-n=15)$. Fifteen further cases were notified in error: 11 were cases of haemolytic disease of the newborn, two were cases in which the report card was incorrectly marked, and two were duplicates.

This paper is concerned with the 27 confirmed and probable cases of haemorrhagic disease of the newborn. Table I gives the clinical details. The two probable cases were in babies born at term who were solely breast fed. The first (case 4 ; table I) received no vitamin $\mathrm{K}$ prophylaxis and at about 1 week developed blood in the stools and nose bleeds, which continued intermittently until about 6 weeks; at that stage the

Dr McNinch.

BMF 1991;303:1105-9 


\begin{tabular}{|c|c|c|c|c|c|c|c|c|c|c|}
\hline $\begin{array}{l}\text { Case } \\
\text { No }\end{array}$ & $\begin{array}{l}\text { Vitamin } \\
\text { K given }\end{array}$ & Feed type & $\begin{array}{c}\text { Age at } \\
\text { onset } \\
\text { (days) }\end{array}$ & $\begin{array}{c}\text { Age at } \\
\text { presentation } \\
\text { (days) }\end{array}$ & Bleeding site & $\begin{array}{l}\text { Warning } \\
\text { bleeds } \\
\text { or delay }\end{array}$ & $\begin{array}{l}\text { Prothrombin } \\
\text { time (s } \\
\text { or ratio) }\end{array}$ & $\begin{array}{l}\text { Kaolin- } \\
\text { cephalin } \\
\text { or partial } \\
\text { thrombo- } \\
\text { plastin } \\
\text { time (s) }\end{array}$ & Liver problem & Outcome \\
\hline 1 & Nil & Breast & 36 & 37 & Bruising & Delay & $>360$ & $>365$ & & No data \\
\hline 2 & Nil & Breast & 3 & 3 & Bruising & & 106 & 90 & & No concern \\
\hline 3 & Nil & Breast & 43 & 44 & Bruising & Delay & $>180$ & $>300$ & Jaundice & No concern \\
\hline $4^{\star}$ & Nil & Breast & 7 & & Gastrointestinal tract & Delay & ND & ND & & No concern \\
\hline 5 & Nil & Breast & 30 & 31 & Gastrointestinal tract & Delay & $>200$ & $>200$ & & No concern \\
\hline 6 & Nil & Breast & 3 & 4 & Gastrointestinal tract & Delay & 34 & 75 & & No concern \\
\hline 7 & Nil & Breast & 4 & 4 & Gastrointestinal tract & & 29 & 130 & & No concerr \\
\hline 8 & Nil & Breast & 2 & 2 & Gastrointestinal tract & & 27 & 90 & & No concerr \\
\hline 9 & Nil & Cows' milk & 2 & 2 & Gastrointestinal tract & & $29+$ & 100 & & No concerr \\
\hline \multirow[t]{2}{*}{10} & Nil & Mixed breast and & & & & & & & & \\
\hline & & cows' milk & 5 & 5 & Gastrointestinal tract & & 25 & 64 & & No concerr \\
\hline 11 & Nil & Breast & 14 & 14 & Intracranial haemorrhage + bruising & & $>360$ & $>360$ & & Concern \\
\hline 12 & Nil & Breast & 31 & 45 & Intracranial haemorrhage & Nose & 67 & 67 & & Died \\
\hline 13 & Nil & Breast & 34 & 35 & Intracranial haemorrhage & Bruising & 180 & 180 & & Concern \\
\hline 14 & Nil & Breast & 23 & 28 & Intracranial haemorrhage & Bruising & 46 & 112 & & Concern \\
\hline 15 & Nil & Breast & 6 & 17 & Intracranial haemorrhage & Umbilical & $>180$ & $>180$ & $\alpha_{1}$ Antitrypsin deficiency & Concern \\
\hline 16 & Nil & Breast & 13 & 13 & Umbilical & & $7 \cdot 0: 1$ & 182 & & No concern \\
\hline 17 & Nil & Breast & 4 & 14 & Umbilical & Delay & 166 & $>180$ & & No data \\
\hline 18 & Nil & Breast & 7 & 7 & Umbilical & & 154 & $>180$ & Hepatitis & No concern \\
\hline 19 & Nil & Breast & 4 & 4 & Urine & & $>120$ & 85 & & No concern \\
\hline 20 & Nil? & Breast & 2 & 2 & Gastrointestinal tract & & 70 & 80 & & No concern \\
\hline 21 & Oral & Soy milk & 36 & 38 & Bruising & Delay & 98 & 98 & & No concern \\
\hline 22 & Oral & Breast & 36 & 38 & Gastrointestinal tract & Bruising & $>122$ & $>110$ & $\alpha_{1}$ Antitrypsin deficiency & No concern \\
\hline $23^{\star}$ & Oral & Breast & 30 & 37 & $\begin{array}{l}\text { Gastrointestinal tract + intracranial } \\
\text { haemorrhage }\end{array}$ & $\begin{array}{l}\text { Gastrointestinal } \\
\text { tract }\end{array}$ & ND & ND & & Died \\
\hline 24 & Oral & Breast & 26 & 29 & Intracranial haemorrhage & Delay & $6 \cdot 4: 1$ & 120 & & Concern \\
\hline 25 & Oral & Breast & 43 & 49 & Intracranial haemorrhage & Nose & 39 & 56 & Hepatitis & Concern \\
\hline 26 & Oral & Breast & $? 60$ & 60 & Intracranial haemorrhage & Bruising & 60 & 100 & $\alpha_{1}$ Antitrypsin deficiency & Concern \\
\hline 27 & Oral? & Breast & 40 & 40 & $\begin{array}{l}\text { Gastrointestinal tract + intracranial } \\
\text { haemorrhage + venepuncture }\end{array}$ & & $>120$ & $>180$ & $\alpha_{1}$ Antitrypsin deficiency & Concern \\
\hline
\end{tabular}

$\mathrm{ND}=$ Not done.

†Tested one hour after treatment with fresh frozen plasma and intramuscular vitamin $K_{1}$.

mother changed to formula feeding and the bleeding stopped. The other baby (case 23), of Pakistani parents, was born by breech delivery at 42 weeks, weighed $2280 \mathrm{~g}$, received oral vitamin $\mathrm{K}_{1} 1 \mathrm{mg}$, but vomited once within 12 hours and the dose was not repeated. In subsequent weeks the baby's weight increased parallel to but below the third centile. In the fifth week the stools became darker and contained a small amount of blood. On day 36 the baby became distressed and cold, then started convulsing. She was taken to hospital but died in the casualty department before any investigations could be done. Postmortem examination showed no external marks of violence, and no bony injury was seen on radiography. Further examination showed an extensive, acute subdural haemorrhage and herniation of both uncinate lobes.

When the survey began in March 1988 paediatricians were asked to report cases of haemorrhagic disease of the newborn seen in the previous three months. Subsequently they reported, each month, only cases seen in the preceding month. The first reported case was in an infant who was born in December 1987 and presented in the same month. The remaining 26 cases were in infants born in the calendar years $1988-9$, and their data were analysed by using the birth statistics of those years.

Fewer patients were born in the second half of 1989 (four cases, none after September) than in the other six month periods. More of the patients were born in the spring and summer quarters (April to September) than in autumn and winter in both 1988 (11/15 total) and 1989 (8/11 total), so that (with the years combined) 19 of the 26 infants were born in these warmer months. Numbers of births in the British Isles were almost identical in these two periods (total births for the April to September periods of 1988 and 1989 were 841000 and for the October to March periods 829000 ). The relative risk of the disease in an infant born in the April to September period was thus $2 \cdot 67$ (95\% confidence interval $1 \cdot 12$ to $6 \cdot 36$ ). Twenty three babies were white, and there was one each of Asian, Caribbean, oriental, and mixed race parentage. All were mature infants (gestational age 36-40 (median 40) weeks) and of good birth weight (2280-3800 g; mean $3186 \mathrm{~g})$. One baby was born by breech delivery with forceps to the head; all others were born by normal vaginal delivery. In 10 of the 27 cases the bleed which precipitated admission was an intracranial haemorrhage, although in seven of these there were preceding warning bleeds.

Vitamin $K$ prophylaxis - Nineteen infants had not been given vitamin $\mathrm{K}$ prophylaxis, and six had received oral vitamin $\mathrm{K}$ ( $1 \mathrm{mg}$ in five cases, $0.5 \mathrm{mg}$ in one). In two cases there were no data about prophylaxis. One baby (case 20) was born in a unit where the policy was to give intramuscular prophylaxis to all babies and the case notes stated that it had been given. However, the father, who was present at delivery and subsequently, was sure that no injection had been given. The staff were unable to confirm the injection, and the reporting paediatrician concluded that vitamin $\mathrm{K}$ had not been given. This case is therefore included in the "no prophylaxis" group. The other baby (case 27) was born in a unit where oral prophylaxis was routine but there was no record that the baby had received it; this patient is presumed to have received oral prophylaxis to prevent any underestimate of the size of this group.

Feeding-Twenty four babies were solely breast fed. One (case 10) received a single formula feed on the first day of life but was otherwise breast fed, was given no vitamin $\mathrm{K}$ prophylaxis, and presented on day 5 with blood in the stools. Two babies were primarily bottle fed. One of these (case 9) received no prophylaxis, took very few feeds in the first 24 hours, and presented at 30 hours with shock caused by a large gastrointestinal haemorrhage. The other baby (case 21 ) received oral vitamin $K_{1} 0.5 \mathrm{mg}$, was fed on a soy milk formula, and presented with spontaneous bruising at 38 days, when non-accidental injury was suspected until the abnormal clotting was found. The importance of breast feeding as a risk factor could not be investigated with precision statistically as data for breast feeding in this population (median age 19 days) were not collected. Nevertheless, data collected by the Office of Population Censuses and Surveys suggest that $40 \%$ of an age matched sample of infants in the general population 
would be breast fed, which allows calculation of a relative risk ratio of haemorrhagic disease of the newborn in breast fed infants of 12.0 (95\% confidence interval 3.6 to 39.8 ) compared with bottle fed infants.

Other medication - In only one pregnancy (case 2) did the mother take any medication other than iron and vitamins - namely, phenytoin for epilepsy. The baby was not given prophylaxis, was solely breast fed, and presented on day 3 with bruising. Only one baby (case 25) received medication other than vitamins before presenting with haemorrhagic disease of the newborn. He had been given Dentinox drops (dimethicone) for colic for eight days.

Age at presentation - The figure illustrates the ages at presentation of the whole group and the subgroups of those presenting with intracranial haemorrhage, those with liver disease, and those with both conditions. Table II compares the ages at onset and presentation of babies given oral vitamin $\mathrm{K}$ and those given no prophylaxis. Babies who received oral prophylaxis had a later onset and presentation of bleeding.

Warning bleeds and delayed presentation-In 14 cases there was a recorded delay of 1-14 days (median 2 days) between the first manifestation of clotting disorder (bruising, nose bleeds, umbilical oozing, etc) and presentation (excludes case 4). Six of these babies suffered intracranial haemorrhage 1-14 days (median 5.5 days) after their first warning bleed. One other baby (case 24) presented with intracranial haemorrhage alone after a three day delay.

Liver disease-Liver function was tested in 10 of the 27 babies and abnormalities found in seven. Six were found to have hepatitis, the result of $\alpha_{1}$ antitrypsin deficiency in four cases and of unknown cause in two. The other baby had persistent unconjugated hyperbilirubinaemia (serum bilirubin concentration $60 \mu \mathrm{mol} / 1$ on day 44) with high alkaline phosphatase (1110 IU/l) but normal aspartate transaminase (28 IU/l) activities.

Other predisposing factors - No baby was reported to have other factors said to predispose to haemorrhagic disease of the newborn, such as diarrhoea, treatment with antibiotics, cystic fibrosis, or biliary atresia.

Outcome - Fifteen babies survived without sequelae, and two others, for whom information was lacking, were presumed well from their mode of presentation. Morbidity and mortality were confined to the 10 babies who presented with intracranial haemorrhage. Among

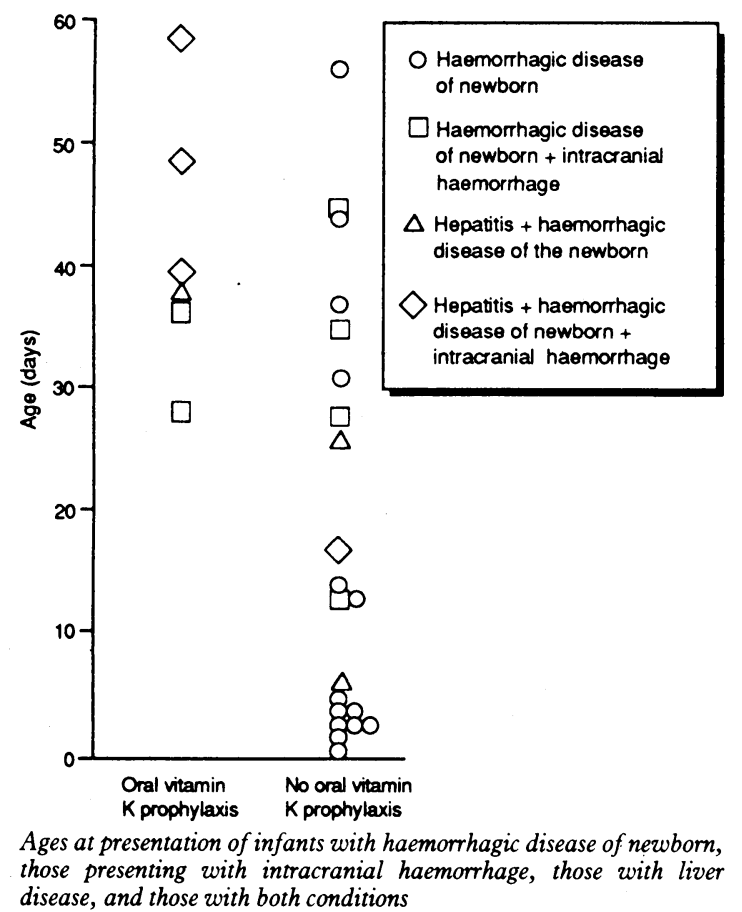

TABLE II-Comparison of ages at onset of bleeding tendency and presentation with haemorrhagic disease of newborn in babies given no prophylaxis and those given oral vitamin $K_{I}$

\begin{tabular}{|c|c|c|}
\hline & $\begin{array}{l}\text { Age at onset } \\
\text { (days) }\end{array}$ & $\begin{array}{l}\text { Age at presentation } \\
\text { (days) }\end{array}$ \\
\hline $\begin{array}{l}\text { No vitamin } K(n=20) \\
\text { Oral vitamin } K 0 \cdot 5-1.0 \mathrm{mg}\end{array}$ & $\begin{array}{l}2-43(\text { median } 6 \cdot 5) \\
26-60(\text { median } 36)\end{array}$ & $\begin{array}{l}2-45(\text { median } 13 \cdot 5) \\
29-60(\text { median } 38)\end{array}$ \\
\hline Wilcoxon's ranked sum test & $\mathrm{p}<0.001$ & $\mathrm{p}<0.01$ \\
\hline
\end{tabular}

TABLE III - Derived rates and relative risks of haemorrhagic disease of newborn in groups of infants receiving different prophylactic regimens

\begin{tabular}{|c|c|c|c|c|}
\hline Group & $\begin{array}{l}\text { No of } \\
\text { cases }\end{array}$ & $\begin{array}{l}\text { Birth } \\
\text { population } \\
\text { at risk in } \\
\text { two years }\end{array}$ & $\begin{array}{c}\text { Rate of } \\
\text { haemorrhagic } \\
\text { disease of } \\
\text { newborn (per } \\
100000 \text { ) }\end{array}$ & $\begin{array}{c}\text { Relative risk } \\
\text { 95\% confidence } \\
\text { interval })\end{array}$ \\
\hline $\begin{array}{l}\text { No prophylaxis } \\
\text { Oral prophylaxis: }\end{array}$ & 19 & $<220000$ & $>8.63$ & $81 \cdot 7(11$ to 610$)$ \\
\hline $\begin{array}{l}\text { All babies } \\
\text { Babies without }\end{array}$ & 7 & $<493000$ & $>1.42$ & $13.4(1.65$ to 109$)$ \\
\hline $\begin{array}{l}\text { liver disease } \\
\text { Intramuscular }\end{array}$ & 3 & $<493000$ & $>0.61$ & $5.75(0.59$ to 55$)$ \\
\hline prophylaxis & 0 & $<945000$ & $<0.11$ & $1 \cdot 0$ \\
\hline
\end{tabular}

See text for notes on derivation of figures. Birth population derived from data of Handel and Tripp.

these, two babies died, and two others required neurosurgery, and concern was expressed about future development in all the survivors.

Risk of haemorrhagic disease of the newborn-Relative risks for development of haemorrhagic disease of the newborn can be estimated from these data and those of Handel and Tripp ${ }^{3}$ (table III) with the following caveats. Firstly, we have assumed that the data on vitamin $\mathrm{K}$ prophylaxis policy in the United Kingdom ${ }^{3}$ are representative of the whole of the British Isles (that is, including the Republic of Ireland), the population base of this survey. The limited returns from the Republic of Ireland suggest that this is a reasonable assumption (Handel and Tripp, unpublished observations). Secondly, the rates calculated for the no prophylaxis and oral prophylaxis groups are minima because in each case the true population at risk would be smaller than that used in the calculation, some babies being selected to receive intramuscular prophylaxis on the grounds of prematurity or other risk factors. Thirdly, we have made the most pessimistic assumption for the intramuscular prophylaxis group, that the next baby born in this population would have developed haemorrhagic disease of the newborn.

\section{Discussion}

Twenty seven cases of haemorrhagic disease of the newborn were reported among 1671000 live births, a rate per 100000 births of $1.62(95 \%$ confidence interval 0.998 to $2 \cdot 24)$. The data confirm that haemorrhagic disease of the newborn remains a cause of serious morbidity and mortality in the British Isles-in two years causing intracranial haemorrhage in 10 infants, two of whom died. The data also confirm that exclusive breast feeding is an important risk factor ${ }^{6.9}$ and that so called late haemorrhagic disease of the newborn (that is, presentation after the first week of life) is relatively common and frequently associated with intracranial haemorrhage. $^{789 \mathrm{a}}$ The increased incidence noted in the period April to September is consistent with the reported higher incidence during the warm season in Japan.?

It is estimated that in the British Isles some 200000 babies per annum are born in units where the routine prophylaxis is vitamin $\mathrm{K}_{1} 1 \mathrm{mg}$ given orally. ${ }^{3} \mathrm{Com}$ pared with those who received intramuscular vitamin $\mathrm{K}$ there was an increased risk of haemorrhagic disease of the newborn among babies given oral prophylaxis 
(relative risk $13 \cdot 4 ; 95 \%$ confidence interval 1.65 to 109 ) and a greatly increased risk among those given no prophylaxis $(81 \cdot 7 ; 11$ to 610$)$. In the absence of liver disease the increased risk associated with oral prophylaxis did not quite achieve significance (relative risk $5 \cdot 8 ; 0.6$ to 55 ), but as liver disease is rarely diagnosed at birth when prophylaxis is given and as in no case of haemorrhagic disease of the newborn was liver disease suspected before presentation with bleeding (see below) the distinction seems irrelevant in clinical practice.

As no confirmed case of haemorrhagic disease of the newborn was reported in a baby who had definitely received intramuscular vitamin $K_{1}$ we conclude that this method of prophylaxis protects against the disease, even in babies with liver disease; reports to the contrary are exceedingly rare.$^{8}$ In a recent survey of haemorrhagic disease of the newborn in Germany, where about $80 \%$ of units practise prophylaxis for all babies, three of the 14 reported cases were in babies who had received a single oral dose of vitamin $\mathrm{K}_{1}$, one in a baby who had received an intramuscular dose (1 $\mathrm{mg}$ ), and the remainder in babies who had received no prophylaxis ( $R$ Von Kries, personal communication).

Haemorrhagic disease of the newborn was reported in only one baby born to a mother taking anticonvulsant medication, but we cannot conclude that the risk to such babies has been overemphasised in the past. ${ }^{10} \mathrm{~A}$ more likely explanation is that it is rare for these babies not to be given intramuscular vitamin $K_{1}$, even in maternity units practising a selective policy for prophylaxis, though interestingly this was not reported as being a common indication for prophylaxis in such units. $^{3}$

The figure and table II show that infants who developed haemorrhagic disease of the newborn after oral vitamin $\mathrm{K}$ prophylaxis presented later than those who were given no prophylaxis. It may be inferred that oral prophylaxis at birth protects against haemorrhagic disease of the newborn in the early weeks of life. In many this is enough to give complete protection because during this "protected" period they may be changed from breast feeding to formula milk supplemented with vitamin $\mathrm{K}$. In others, however, after the early weeks the risk of haemorrhagic disease of the newborn may increase again if they remain breast fed and particularly if they have liver disease.

It is noteworthy that 14 babies, seven of whom later suffered an intracranial haemorrhage, had either warning bleeds before presenting with haemorrhagic disease of the newborn or a delay of at least one day before presentation and that in one probable case the haemorrhagic tendency resolved when the baby was changed from breast feeding to formula milk. Midwives, health visitors, and doctors must be aware that bleeding, even in an apparently well baby, requires urgent investigation. Bleeding from the gut, nose bleeds, spontaneous bruises, and persistent oozing from the umbilicus or after Guthrie testing must not be ignored as they may presage catastrophic haemorrhage. Babies other than those reported to this study may have had significant symptoms which were never brought to the attention of a paediatrician because they did not have a major bleed before their haemorrhagic tendency resolved spontaneously.

\section{LIVER DISEASE}

It could be argued that babies with liver disease should have been excluded from the data because their haemorrhage was secondary to the underlying condition. However, we believe the essential point is that they, like the others, bled as a result of vitamin $\mathrm{K}$ deficiency, which is potentially preventable by prophylaxis. Hepatitis is clearly an important risk factor for such bleeding even after oral prophylaxis with vitamin $K_{1} 1 \mathrm{mg}$. In this series there were six cases of hepatitis, and in none was it suspected until after the presentation with bleeding. Hepatitis cannot be diagnosed clinically at birth, so these babies cannot be recognised as being at high risk of developing haemorrhagic disease of the newborn at the time when vitamin $\mathrm{K}$ is usually given; if a selective policy of prophylaxis is used they are likely to be selected for no prophylaxis.

It is extremely unlikely that there were no cases of neonatal hepatitis among the babies given intramuscular vitamin $K_{1}$ (the substantial majority of newborns in the United Kingdom ${ }^{3}$ ), yet none developed haemorrhagic disease of the newborn in the study period and it is much more likely that they were protected. In some the hepatitis may have resolved spontaneously without ever causing concern or being diagnosed, while others would have presented with features of liver disease other than bleeding. Mild cholestasis has been identified in a number of infants presenting with late onset haemorrhagic disease of the newborn, but in our study there was only one other patient with a history of prolonged jaundice.

All British paediatricians were made aware of the reasons for this survey at the outset, perhaps increasing awareness of the dangers of haemorrhagic disease of the newborn, and preliminary data were presented to the British Paediatric Research Society in April 1989 and published by the British Paediatric Surveillance Unit in 1988. ${ }^{11}$ These factors may have influenced vitamin $\mathrm{K}$ prophylaxis policy in some units as the study progressed, and it is notable that we received no notifications of confirmed or probable cases in the last five months of the study.

We are faced with the physiological conundrum that infants seem to be born with less vitamin $K$ than is optimal for survival in the first three months of life, and it may be that there is a biological advantage, as yet unknown, of relative vitamin K deficiency at that time. A recent report, given extensive coverage in a national newspaper, suggested that infants given vitamin $\mathrm{K}$ at birth are more likely to develop cancer in later childhood, though the authors were careful to point out that their findings may have resulted from chance associations or dependent variables and need to be confirmed..$^{12}$ Nevertheless, the possible link with later disease lends weight to the view that we should use the minimum effective dose of vitamin $\mathrm{K}$ for prophylaxis.

We believe that all babies should receive vitamin $K$ prophylaxis. A $1 \mathrm{mg}$ intramuscular dose of vitamin $\mathrm{K}_{1}$ protects against haemorrhagic disease of the newborn but there are proper concerns about the small risk of intramuscular injections in neonates and about undue medical intervention in the process of normal childbirth. The same prophylactic dose given orally at birth does not protect all babies, particularly those with liver disease, but it may delay the onset of bleeding, implying partial protection. We also recognise that an oral dose might be spat out or vomited, so if this method is to be used a schedule of repeated doses should be considered, as is standard practice in Japan.? Newer preparations of phytomenadione undergoing trials are much better absorbed by the oral route ( $\mathrm{H}$ Grüter, personal communication) but for the present we have elected to use intramuscular prophylaxis for all neonates in Exeter.

We thank the British Paediatric Surveillance Unit and its sponsors Children Nationwide, all the paediatricians who reported cases and supplied further details, Dr Clive Lawrence for statistical advice, and Roche Products Ltd for financial support. We also thank Dr Jeffrey Handel, Mrs Ann Hoskins, and Miss Debbie Perry for advice and assistance.

1 Dam H, Dyggve H, Hjalmar L, Plum P. The relation of vitamin $\mathrm{K}$ deficiency to hemorrhagic disease of the newborn. Adv Pediatr 1952;5:129-53.

2 Tripp JH, McNinch AW. Haemorrhagic disease and vitamin K. Arch Dis Child 1987;62:426-7. 


\section{Department of Child Health,Postgraduate Medical School, Heavitree, Exete EX2 5SQ \\ Jeffrey Handel, MB, registrar in paediatrics \\ John H Tripp, MD, senio \\ lecturer in child health}

Correspondence to: Dr Tripp.

BMf 1991;303:1109
3 Handel J, Tripp JH. Vitamin $\mathrm{K}$ prophylaxis against haemorrhagic disease of the newborn. $B M F$ 1991;303:1109.

4 Hall SM, Glickman M. The British Paediatric Surveillance Unit. Arch Dis Child 1988;63:344-6.

5 Martin J, White A. Infant feeding 1985. A survey carried out for the DHSS and the Scottish Home and Health Department by the Office of Population Censuses and Surveys. London: HMSO, 1988.

6 Sutherland JM, Glueck HI, Gleser G. Hemorrhagic disease of the newborn. Breast feeding as a necessary factor in the pathogenesis. Am $\mathcal{f}$ Dis Child 1967;113:524-33.

7 Hanawa Y, Maki M, Matsuyama MD, et al. The third nationwide survey in Japan of vitamin K deficiency. Acta Paediatr fpn 1990;32:51-9.

8 Kries R von, Shearer MJ, Gobel U. Vitamin $\mathrm{K}$ in infancy. Eur $\mathcal{f}$ Pediat 1988;147:106-12.

\section{7 \\ Vitamin K prophylaxis against haemorrhagic disease of the newborn in the United Kingdom}

\author{
Jeffred Handel, John H[Tripp
}

9 Tonz O, Schubiger G. Neonatale Vitamin-K-Prophylaxe und Vitamin-KMangelblutungen in der Schweiz 1986-1988. Schweiz Med Wochensch 1988;118:1747-52

9a Ekelund H. Late haemorrhagic disease in Sweden 1987-9. Acta Paediatr Scand 1991;80:966-8.

10 Mountain KR, Hirsh J, Gallus AS. Neonatal coagulation defect due to anticonvulsant drug in pregnancy. Lancet 1970;i:265-8.

1 British Paediatric Surveillance Unit. Third annual report 1988. London: BPSU, 1988.

2 Golding J, Paterson M, Kinlen LJ. Factors associated with childhood cancer in a national cohort study. Br f Cancer 1990;62:304-8.

(Accepted 16 August 1991)

units gave $1 \mathrm{mg}$ vitamin $\mathrm{K}$ orally or intramuscularly. Other doses for routine prophylaxis were: intramuscular $0.5 \mathrm{mg}$ (17 units) and $0.25 \mathrm{mg}$ (two); oral 0.5 $\mathrm{mg}$ (three), $0.25 \mathrm{mg}$ (two), and $2.0 \mathrm{mg}$ (one). Eighty one units reduced the dose for preterm and low birthweight babies.

Reports of haemorrhagic disease of the newborn were the main reason for changing to a policy of prophylaxis for all. Oral administration was increasingly used because of awareness that vitamin $K$ is well absorbed by this route, ${ }^{3}$ concern about inadvertent use of intramuscular ergometrine-oxytocin, and general reluctance to give intramuscular injections. itamin $\mathrm{K}$ prophylactically to protect neonates haemorrhagic disease of the newborn. ${ }^{1}$ The finding of an association between use of vitamin $\mathrm{K}_{3}$ and kernicterus in premature babies in the 1960s was a setback. Vitamin $\mathrm{K}_{1}$ was safe in this respect but the rarity of haemorrhagic disease of the newborn, the trauma of intramuscular injections, and the cost of treating all babies have been the cause of continuing debate. ${ }^{2}$ Some paediatricians maintain that the only safe practice is to give intramuscular vitamin $\mathbf{K}$ to all babies, others that oral vitamin $\mathrm{K}$ suffices in those at low risk for haemorrhagic disease of the newborn, and a minority that this second group needs no prophylaxis at all.

The aims of this study were to document current patterns of prophylaxis policy in Great Britain and Northern Ireland, recording recent changes and determining the reasons for these changes.

\section{Methods and results}

In 1988 a questionnaire was sent to each special care baby unit in the United Kingdom (as listed by the Neonatal Nurses' Association) requesting information about policies of prophylaxis in each maternity unit they served, aimed at including all maternity unit deliveries. We asked which babies received prophylaxis, the route of administration, the dose, whether repeat doses were given, whether changes in policy had been made since 1982 and, if so, why. The total number of yearly deliveries in the catchment of each unit was established. Replies were received from 278 $(87 \%)$ of identified units. Excluding tertiary referral units we received data from 255 units accounting for roughly 592000 deliveries a year (three quarters of all deliveries).

All units gave vitamin $\mathrm{K}$ (phytomenadione) to all or selected babies either intramuscularly, orally, or, rarely, intravenously. Of 219 units that gave all babies vitamin $\mathrm{K}$, in 152 this was by intramuscular injection. Sixty seven units gave oral vitamin $\mathrm{K}$ routinely, and in 64 of these, babies considered at high risk received vitamin $\mathrm{K}$ intramuscularly; in one unit babies considered to be at high risk received vitamin $\mathrm{K}$ intravenously. Thirty six units gave vitamin $\mathrm{K}$ only to selected babies considered to be at high risk ( 33 intramuscular, three oral vitamin $\mathrm{K}$ ). One hundred and fifteen units gave supplementary doses to high risk babies.

Since 1982 there had been a shift towards a policy of prophylaxis for all babies and from intramuscular to oral administration as routine (figure). A total of 220

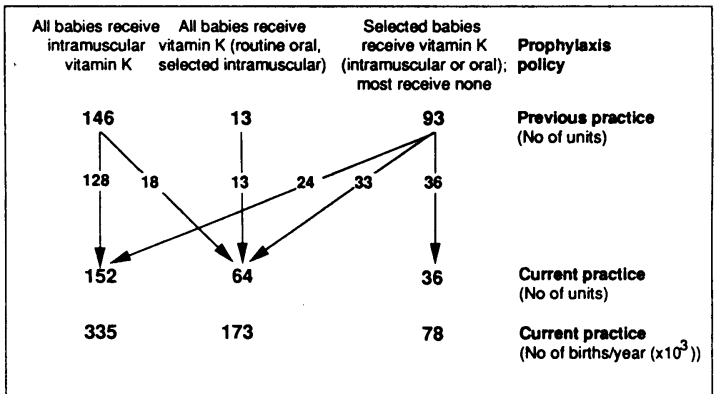

Changes in policy for vitamin $K$ prophylaxis in special care baby units in United Kingdom

\section{Comment}

All special care baby units give vitamin $\mathrm{K}$ to at least some babies; $510000(86 \%)$ babies a year were born in units where all received intramuscular or oral vitamin $\mathrm{K}$.

A total of $78000(13 \%)$ babies were born in units of high risk infants were selected to receive vitamin $\mathrm{K}$. Very few units selected for prophylaxis babies who were breast fed or whose mothers took anticonvulsant or antituberculous drugs during pregnancy, although these are recognised risk factors for haemorrhagic disease of the newborn. Thus around $13 \%$ of breast fed babies born in the United Kingdom do not receive vitamin $\mathrm{K}$. These babies are at risk of developing haemorrhagic disease of the newborn. ${ }^{4}$ widespread and the use of oral vitamin $\mathrm{K}$ has increased. Subcutaneous administration of vitamin $\mathbf{K}$, which gives comparable blood concentrations to intramuscular administration, is not practised in the United Kingdom. The preparation for oral or subcutaneous administration (Konakion) is not licensed for adminis-

1 Lehman J. Vitamin K as prophylaxis in 13000 infants. Lancet 1944;i:493-4

2 Tripp JH, McNinch AW. Haemorrhagic disease and vitamin K. Arch Dis Child 1987;62:436-7.

3 McNinch AW, Upton C, Samuels M, Shearer MJ, McCarthy P, Tripp JH, et al. Plasma concentrations after oral or intramuscular vitamin $K_{1}$ in neonates. Arch Dis Child 1985;60:814-8.

$4 \mathrm{McNinch}$ AW, Tripp JH. Haemorrhagic disease of the newborn in the British Isles: two year prospective study. BMF 1991;303:1105-9.

(Accepted 16 August 1991) where most received no vitamin $\mathrm{K}$ and a small minority

Since 1982 routine prophylaxis has become more tration by these routes in the United Kingdom. 